\title{
Male Physical Fighting Ability During Adolescence Is Influenced by Height and Bulk
}

\author{
Kevin M. Beaver ${ }^{1,2}$ - Eric J. Connolly ${ }^{3}$. \\ Joseph A. Schwartz ${ }^{4}$
}

Received: 7 August 2015 / Revised: 27 October 2015 / Accepted: 11 November 2015 /

Published online: 19 November 2015

(C) Springer International Publishing AG 2015

\begin{abstract}
Introduction A topic often overlooked in the criminological literature is whether and to what extent biological or developmental male characteristics explain variation in fighting ability during adolescence. The current study was designed to add to the existing literature on this topic by examining whether two physical attributes - height and bulk - were associated with being a skilled fighter during this life-course period. Methods and Materials Data for the current study were drawn from the National Longitudinal Survey of Adolescent to Adult Health. Self-reports from male respondents regarding previous fighting experiences were used to assess skilled physical fighting ability. Self-reports of height and bulk were used to assess male physicality. A series of logistic regression models were estimated to examine the associations between fighting ability, height, and bulk.

Results Analysis of adolescent males revealed that taller and bulkier males were significantly more likely to be characterized as a skilled physical fighter. These significant associations could not be explained by whether they had any fighting experience or whether they had used weapons in physical fights.

Conclusions Overall, the results suggest that height and bulk are two observable biological indicators of skilled physical fighting among males.
\end{abstract}

Eric J. Connolly

ejc22@psu.edu

1 College of Criminology and Criminal Justice, Florida State University, Tallahassee,

FL 32306-1127, USA

2 Center for Social and Humanities Research, King Abdulaziz University, Jeddah, Saudi Arabia

3 Department of Criminal Justice, Pennsylvania State University, Abington, 1600 Woodland Road, Abington, PA 19001, USA

4 School of Criminology and Criminal Justice, University of Nebraska at Omaha, Omaha, NE 68182, USA 
Keywords Add health $\cdot$ Bulk $\cdot$ Fighting $\cdot$ Height $\cdot$ Violence

A well-known finding in the developmental and criminological research is that adolescents represent the most criminal age group [1-3]. They are disproportionately involved in acts of crime and delinquency, they use and abuse drugs at relatively high rates, and they engage in other forms of risky behaviors on a widespread basis. Against this backdrop, it is probably not surprising that adolescents are also disproportionately overinvolved in acts of serious aggression, including physical fighting. Each year, somewhere between 10 and $11 \%$ of adolescents are involved in physical fights in the USA, which translates into a rate of about 1 out of every 10 youth [4]. Not surprisingly, males are much more likely to engage in physical fighting than females, with recent estimates indicating that males are more than twice as likely, compared to females, to be involved in a physical fight in a given year [4]. Although the majority of these physical fights are relatively benign and result in nothing more than minor cuts and abrasions, some fights do produce serious physical harm and injury, including broken bones and concussions. While most youth eventually recover from the physical pain caused by even the most serious fighting-related injuries, there can be long-term negative effects ranging from emotional trauma to long-term reductions in intelligence [5].

Given the relatively frequent occurrence of youthful fighting and the serious injuries that can result, there has been a great deal of research examining the potential causes that predict physical fighting during adolescence [6-8]. This line of work has identified a broad array of risk factors, such as exposure to antisocial peers [9], residing in a high-crime neighborhood [10], and being reared in a dysfunctional family [11], that appear to contribute to adolescent fighting. Surprisingly, what has not been explored thoroughly in the criminological literature are the factors that predict the outcome of a physical fight - that is, who is most likely to become the winner and who is most likely to be the loser-particularly for adolescents in the general population ([12]; for notable exceptions, see [13-15]). This is a particularly important omission for two key reasons. First, consistent losers of physical fights are likely to bear the brunt of the negative emotional and physical outcomes associated with physical fighting. It stands to reason that they will suffer the most significant amount of physical damage as well as the most serious emotional trauma that are often associated with being victimized in a physical fight. Second, if there are certain factors that regularly predict who the most consistent winners and losers of physical fights are, then perhaps safeguards can be employed to help reduce individuals from being chronically victimized in physical fights. To illustrate, research has revealed that (1) once an individual is victimized, they are statistically more likely to be victimized again in the future [16] and (2) adolescents who are victimized on a regular basis are at very high risk for suffering from emotional and social problems [17-19]. As a result, identifying the factors that might predict fighting abilities could go a long way toward reducing the number of youth who are frequent victims in physical fights and perhaps help to reduce the incidence of bullying.

At first glance, it seems obvious that winning and losing in a physical fight is determined by an assortment of skill sets, such as hand-eye coordination, muscle power, and proper technique. But, in adolescence, most youth have little-to-no experience in formal fighting training and so other, more random factors that influence the outcome of a physical fight must be at play. One possible factor is physical stature. It seems almost commonsensical to think that adolescents who are taller, heavier, more 
muscular, and bulkier would hold an advantage in a physical fight, but to date, there is only a limited body of research examining this possibility. Most of this research has examined whether physical stature (e.g., height and weight) is associated with antisocial traits and with the probability of engaging in a physical fight. For example, findings from some studies have linked increased height and bulk to antisocial personality disorder [20], size and strength to involvement in acts of physical aggression [21], and body mass to physical aggression [22]. Moreover, there exists a body of research revealing that measures of strength and body size are connected to increases in levels of aggression and dominance [22-24]. None of these studies, however, have directly linked physical stature to fighting success among adolescent youth.

There is one study that has direct application to this possibility. Felson [25] examined the influence of physical size and power as it applies to interpersonal violence. Analysis of data drawn from ex-offenders, ex-psychiatric inpatients, and the general population revealed, not surprisingly, that males are more likely to initiate physical attacks and they are also more likely to produce physical injures whereas females are more likely to be attacked and injured. What was particularly interesting about this study was that this male-female difference in physical attacks and injuries was completely accounted for by including a measure of physical power. In other words, the coefficient for sex was rendered non-significant in four of the five equations predicting violence and injuries after differentials for physical power between the victim and perpetrator were introduced into the multivariate equations.

While the results of this study provided some empirical evidence indicating that malefemale differences in physical attacks and injuries are linked to size, strength, and power differences, this study revealed virtually nothing about physical size as it relates to successful fighting abilities among youth/adolescents. With this in mind, the current study is designed to overcome this gap in the literature by examining the link between height, bulk, and being a skilled physical fighter in a nationally representative sample of adolescents.

\section{Methods}

\section{Data}

Data for this study were drawn from the first two waves of the National Longitudinal Study of Adolescent Health (Add Health; [26]). Detailed information about these data is available in previously published materials [27-29]. Briefly, the Add Health is a fourwave prospective study of a nationally representative sample of American youth who were enrolled in middle or high school during the 1994-1995 academic school year. Approximately 90,000 adolescents participated in the wave 1 in-school component of the study. Self-report surveys were completed by all adolescents who were in attendance on a specified school day at one of the 132 middle or high schools. In order to gain more detailed information and address topics that were more sensitive in nature, a subsample of adolescents was selected to be re-interviewed in their homes between 1994 and 1995. In total, 20,745 youth and 17,700 of their primary caregivers (typically their mothers) were successfully interviewed during the wave 1 in-home component of the study. Approximately 14,738 adolescents participated in the second wave of interviews which took place approximately 1.5 years after the completion of wave 1 
interviews. The last two waves of data were collected in 2001-2002 (wave 3) and 2007-2008 (wave 4) when most of the respondents were in adulthood [27].

Since the current study is concerned with physical fighting during adolescence, all of the analyses were confined to data drawn from waves 1 and 2. Serious types of violent behavior in adulthood may have different etiologies than violent behaviors in adolescence $[2,30]$, and thus we wanted to keep the behavioral outcomes as homogenous as possible in terms of their underlying causes. Moreover, given that the data were drawn from a nationally representative sample, the incidence of physical fighting (particularly with injuries) was relatively rare in adulthood, making it difficult to analyze fighting ability in adulthood. We also restricted our analysis to males because of the low incidence of female physical fighting. The final analytical sample size ranged between $N=1404$ and 7056 and varied based on missing data and certain criteria that were used to measure being a successful physical fighter (more detail provided below).

\section{Measures}

\section{Fighting Measures}

Two different measures of physical fighting were developed, both of which were based on data drawn solely from wave 2. The first measure - referred to as Physical Fighterwas created from a question asking respondents to indicate how often they had been in a serious physical fight during the previous 12 months. Responses to this item were collapsed into a dichotomous variable, such that $0=$ no serious physical fights in the past 12 months and $1=$ at least one serious physical fight in the past 12 months.

The second variable — referred to as Skilled Physical Fighter — was designed to measure how successful the respondent was at fighting. To do so, two questions were used. The first question asked how many times the respondent was in a physical fight in which they were injured and had to be treated by a doctor or nurse. Responses to this item were dichotomized, such that $0=$ never and $1=$ at least once. Similarly, a second question asked how many times the respondent was in a physical fight in which they hurt someone badly enough to need bandages or care from a doctor or nurse. Once again, responses to this item were dichotomized, such that $0=$ never and $1=$ at least once. To measure whether the respondent was a skilled physical fighter, they had to indicate that they (1) had been in at least one serious physical fight during the previous year, (2) had not been injured badly enough to be treated by a doctor or nurse, and (3) that they injured someone badly enough to need bandages or care from a doctor or nurse. ${ }^{1}$ In short, the statistical equations predicting being a skilled physical fighter were based on data that had been filtered and included male respondents who were in physical fights without being injured during the previous year. The

\footnotetext{
${ }^{1}$ We opted to dichotomize these variables to create the skilled physical fighter variable for two reasons. First, most of the respondents - even those who had been in a physical fight - did not indicate that they received serious injuries or that they inflicted serious injuries on their opponent. Second, the response sets for the two variables (i.e., whether the respondent received injuries and whether their opponent sustained any injuries) were different, with one being measured on the interval scale and the other being measured on the ordinal scale. As a result, it would have been nearly impossible to create skilled physical fighter variables without dichotomizing the variables. Nonetheless, future research would benefit greatly by creating additional measures of physical fighting abilities.
} 
outcome variable was the dichotomous variable asking whether the respondent had injured someone badly enough to need bandages or care from a doctor or nurse. The resulting equations thus predicted being a skilled physical fighter, wherein the respondent injured at least one other person in a fight, but they emerged uninjured from the fight.

\section{Physicality Measures}

Two measures of physicality (both measured from wave 1 data) were employed in the current study: height and bulk. First, height was self-reported by respondents during wave 1 interviews. Height is included in the statistical models as a continuous variable measured in total inches. Second, a measure of bulk was included in order to take into account body stature. The measure of bulk was created based on previous research [20, 31] by first standardizing the subject's height and weight (measured in pounds) and then adding a constant of 10 to these standardized variables. Finally, these two variables were multiplied together. Higher values for bulk indicate a greater physical body stature. Table 1 presents the descriptive statistics for the two physicality measures along with all other variables and scales used in the analyses. ${ }^{2}$

\section{Control Variables}

Two variables were included in the analyses as control variables to help reduce the possibility that any statistically significant associations were the result of confounding. First, age was a continuous variable measured in years at wave 1. Second, race was included a dichotomous dummy variable $(0=$ white, $1=$ non-white $)$.

\section{Plan of Analysis}

The analysis for this study proceeds in a series of sequential steps. First, descriptive data for the key variables included in the analyses are presented and discussed. Next, a bivariate correlation matrix is provided so that the zero-order correlations can be inspected. Third, four binary logistic regression models are estimated. Two of these models predict the physical fighter variable (one model includes the height measure and the other includes the bulk measure), and the other two predict the skilled physical fighter variable (one model includes the height measure and the other includes the bulk measure). Keep in mind that the height and bulk covariates are never included in the same model because bulk is a function of height and thus the two are collinear. Last, to assist in the interpretation of the results, we graph the predicted probabilities for significant associations between the physicality measures and the fighting variables.

\footnotetext{
${ }^{2}$ We opted to only examine height and bulk, but not weight in isolation. The reason we excluded weight from the analyses was because we were interested in identifying physically observable factors that might be related to fighting ability. Height is relatively clear-cut in that it is possible to determine height in an objective and meaningful fashion. Weight, however, is much more complex because it is a function, among other variables, of height. Simply including a weight variable in the analysis would not reveal any information that would be meaningful as respondents who weigh more could simply be taller, they could be overweight, or they could have more muscle mass. As a result, we opted to include a measure of bulk that provides a more objective indicator of physical stature than weight would provide.
} 
Table 1 Descriptive statistics for selected Add Health study variables

\begin{tabular}{llll}
\hline & Mean & SD & Min-max \\
\hline Height & 68.40 & 4 & $48-81$ \\
Bulk & 109.25 & 18.66 & $41.05-196.17$ \\
Age & 16.23 & 1.73 & $12-21$ \\
& Frequency & Percentage & \\
Been in serious fight & & & - \\
Yes & 1891 & $26.5 \%$ & - \\
No & 5258 & $73.5 \%$ & - \\
Been seriously injured & & & - \\
Yes & 429 & $23.0 \%$ & - \\
No & 1440 & $77.0 \%$ & - \\
Seriously injured someone & & & - \\
Yes & 871 & $46.6 \%$ & - \\
No & 999 & $53.4 \%$ & \\
Race & & $62.7 \%$ & \\
$\quad$ White & 6434 & $37.3 \%$ & \\
Non-white & 3821 & & \\
\hline
\end{tabular}

\section{Results}

Table 1 presents the descriptive statistics for the selected Add Health study variables that were included in the analyses. One interesting observation from these values is evident when examining the responses for the "been seriously injured" variable and the "seriously injured someone" variable. As can be seen, $23 \%$ of respondents indicated that they had been seriously injured in a fight while $46.6 \%$ of respondents indicated that they had seriously injured someone in a fight. While these values are not impossible to generate, they do hint at the possibility that adolescent males might be more likely to inflate the amount of injuries that their opponents sustained and/or to deflate the number of injuries that they incurred.

Table 2 presents the zero-order correlations for the variables presented in Table 1. This table shows that height and bulk are significantly associated with injuring someone in a fight, suggesting that taller and bulkier adolescent males are more likely to report injuring someone in a fight compared with shorter or less bulky males.

The findings thus far hint at the possibility that height and bulk might be related with fighting outcomes among adolescent males. Whether these findings would extend to a multivariate analysis and where injuries to both parties involved are taken into account is the focus of the next series of analyses. The multivariate analysis began by estimating the effects of height and bulk on being in a physical fight during the past 12 months for the entire sample of males. The first column of Table 3 displays the findings for height. As can be seen, the effect of height on being in a physical fight was non-significant. The same holds true in the second equation, wherein bulk is unrelated to being in a physical fight during the previous year. 
Table 2 Zero-order Pearson correlation matrix for selected Add Health sample variables

\begin{tabular}{|c|c|c|c|c|c|c|c|c|}
\hline & & $\mathrm{X} 1$ & X2 & X3 & X4 & X5 & X6 & X7 \\
\hline $\mathrm{X} 1$ & Height & 1.00 & & & & & & \\
\hline $\mathrm{X} 2$ & Bulk & $.87^{*}$ & 1.00 & & & & & \\
\hline $\mathrm{X} 3$ & Been in a serious fight & -.00 & .01 & 1.00 & & & & \\
\hline $\mathrm{X} 4$ & Seriously injured in a fight & -.01 & -.01 & $\mathrm{n} / \mathrm{a}$ & 1.00 & & & \\
\hline $\mathrm{X} 5$ & Seriously injured someone & $.08^{*}$ & $.10^{*}$ & $\mathrm{n} / \mathrm{a}$ & $.08^{*}$ & 1.00 & & \\
\hline X6 & Age & $.47^{*}$ & $.46^{*}$ & -.02 & $.08^{*}$ & $.06^{*}$ & 1.00 & \\
\hline X7 & Race & $-.10^{*}$ & $-.07 *$ & .01 & $.08 *$ & .04 & .01 & 1.00 \\
\hline
\end{tabular}

$\mathrm{n} / \mathrm{a}=$ this correlation could not be estimated because there was no variability in the "been in a serious fight" variable as all respondents who responded to the seriously injured variables had been in a physical fight

*Indicates significant correlation at the $p<.05$ level, two-tailed test

The last two equations in Table 3 are duplicates of the first two equations, but they are predicting whether each respondent had injured someone badly enough to need bandages or medical care. Keep in mind that these last two equations were estimated only for males who had been in a serious physical fight and had not been injured during the fight. As can be seen, there was a statistically significant association between height and being a skilled physical fighter, such that taller respondents were more likely to be a skilled physical fighter. Very similar results were detected for bulk, wherein respondents scoring higher on the bulk measure were also more likely to be a skilled physical fighter.

Table 3 Logistic regression models predicting being in a Physical Fighter and being a Skilled Physical Fighter with height and bulk

\begin{tabular}{|c|c|c|c|c|c|c|c|c|}
\hline & \multicolumn{4}{|c|}{ Physical Fighter } & \multicolumn{4}{|c|}{ Skilled Physical Fighter } \\
\hline & $b$ & OR & $b$ & OR & $b$ & OR & $b$ & OR \\
\hline \multicolumn{9}{|c|}{ Physicality measure } \\
\hline Height & $\begin{array}{l}.006 \\
(.008)\end{array}$ & 1.006 & & & $\begin{array}{l}.040 \\
(.015)\end{array}$ & $1.040^{*}$ & & \\
\hline Bulk & & & $\begin{array}{l}.003 \\
(.002)\end{array}$ & 1.00 & & & $\begin{array}{l}.010 \\
(.003)\end{array}$ & $1.011^{*}$ \\
\hline \multicolumn{9}{|c|}{ Control variables } \\
\hline Age & $\begin{array}{l}-.30 \\
(.019)\end{array}$ & .970 & $\begin{array}{l}-.038 \\
(.019)\end{array}$ & $.963^{*}$ & $\begin{array}{l}.009 \\
(.038)\end{array}$ & 1.009 & $\begin{array}{l}-.003 \\
(.038)\end{array}$ & .997 \\
\hline Race & $\begin{array}{l}.55 \\
(.056)\end{array}$ & 1.056 & $\begin{array}{l}.059 \\
(.056)\end{array}$ & 1.061 & $\begin{array}{l}.157 \\
(.114)\end{array}$ & 1.170 & $\begin{array}{l}.153 \\
(.114)\end{array}$ & 1.165 \\
\hline $\mathrm{N}$ & 7056 & & 7025 & & 1411 & & 1404 & \\
\hline
\end{tabular}

Physical Fighter=whether the respondent had ever been in a serious physical fight during the previous 12 months; Skilled Physical Fighter=whether the respondent had injured someone in a fight, but they had not been injured in a fight. Standard errors included in parentheses

*Indicates significant coefficient at the $p<.05$ level, two-tailed test; 
The predicted probabilities of being a skilled fighter based on height are presented in Fig. 1. As can be seen, there was a relatively strong and positive association between height and being a skilled physical fighter. The shortest male in the sample was only 48 inches tall and had a predicted probability of being a skilled physical fighter of 0.26 , while the tallest male in the sample who was 79 inches tall had a predicted probability of being a skilled physical fighter of $0.55 .^{3}$ Thus, the tallest male in the sample had more than twice the probability of being a skilled physical fighter than the shortest male in the sample.

In Fig. 2, the predicted probabilities of being a skilled physical fighter (generated from logistic regression equations) were plotted against scores on the bulk measure. In order to facilitate the results and ensure that the predicted probabilities were based on data points that were created from multiple respondents, the original bulk measure was transformed into a quartile measure (note that the bulk measure was only a quartile measure for this figure; for all previous analyses, it was entered into the equations with its original metric). As Fig. 2 reveals, there was a relatively large and positive association between bulk scores and the predicted probability of being a skilled physical fighter. Males who scored in the lowest quartile of bulk had a 0.37 probability of being a skilled physical fighter, while males who scored in the highest quartile of bulk had a 0.48 predicted probability of being a skilled physical fighter.

\section{Supplemental Analysis}

In order to check the robustness of the findings, we also calculated a series of supplemental analyses. These supplemental analyses were designed to control the potential effects of using a weapon in a fight. Specifically, it is possible that taller men who score higher on levels of bulk are more prone to use weapons in a fight. As a result, the effect of height and bulk on being a skilled fighter may be spurious due to the confounding effects of weapon use. We examined this possibility in two ways. First, we re-estimated the logistic regression models by including a dichotomous dummy variable (measured at wave 2) that captured whether the respondent had used a weapon in a fight during the previous 12 months $(0=$ no, $1=$ yes). The results of these models revealed that while the weapon use variable was significantly related to being a skilled fighter, it did not attenuate the effect sizes of the height or bulk measures. Second, we calculated bivariate binary logistic regression models where height and bulk were used as covariates (in two separate equations) to predict using a weapon in a fight. The results of these analyses did not reveal a significant association between height and weapon use $(p=.889)$ or bulk and weapon use $(p=.396)$. These findings merge with recent research which reports no significant association between height and gun ownership [32]. Interestingly, though, the non-significant trend was negative, indicating that taller and bulkier men were, if anything, less likely to use weapons in a fight. Taken together, the results suggest that the findings in respect to height/bulk and skilled physical fighting ability cannot be explained away by the use of weapons.

\footnotetext{
${ }^{3}$ A reviewer commented that the tallest respondent in Table 1 and the tallest respondent in Fig. 1 were of different heights. The reason for this discrepancy is due to the fact that Fig. 1 removes cases via listwise deletion techniques and thus the respondents in Table 1 and Fig. 1 are different owing to missing data on the covariates and variables of interest.
} 


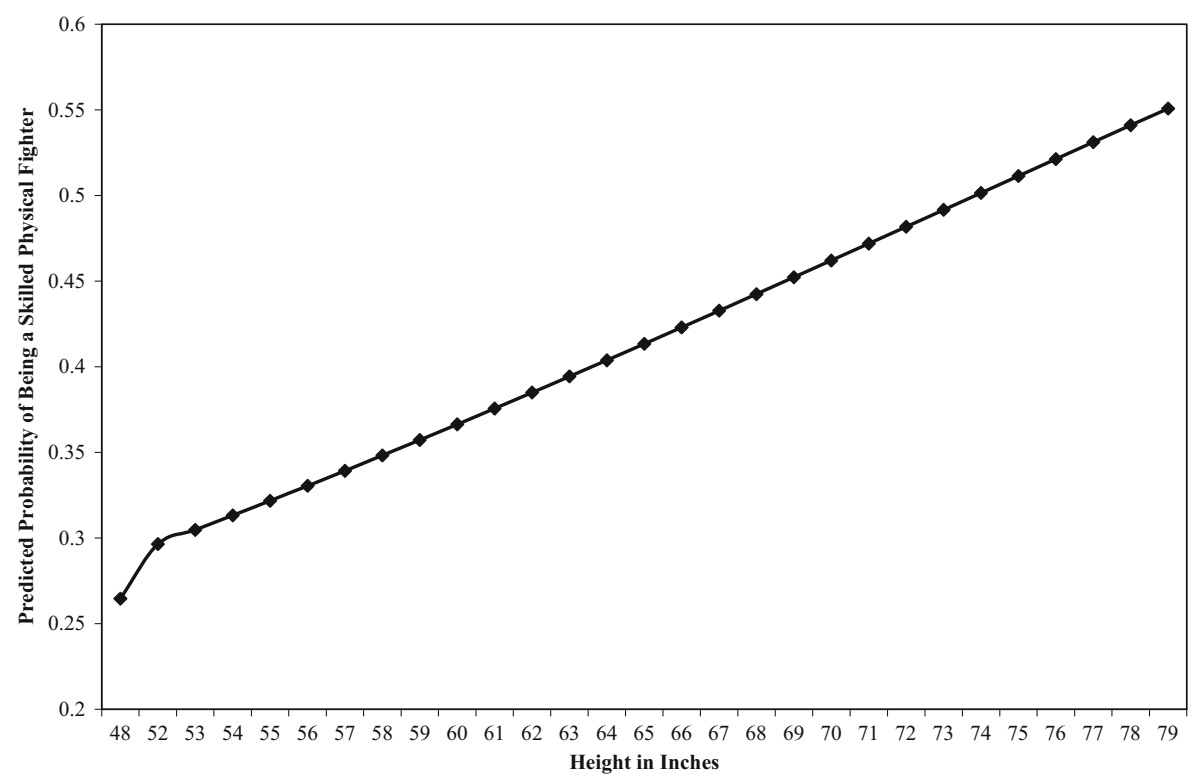

Fig. 1 Predicted probabilities of being a skilled physical fighter across different heights. Note: Predicted probabilities generated with age and race set to their means

\section{Discussion}

Although there has been a significant amount of interest in determining the factors that are related to why youth engage in physical violence, very little research has examined

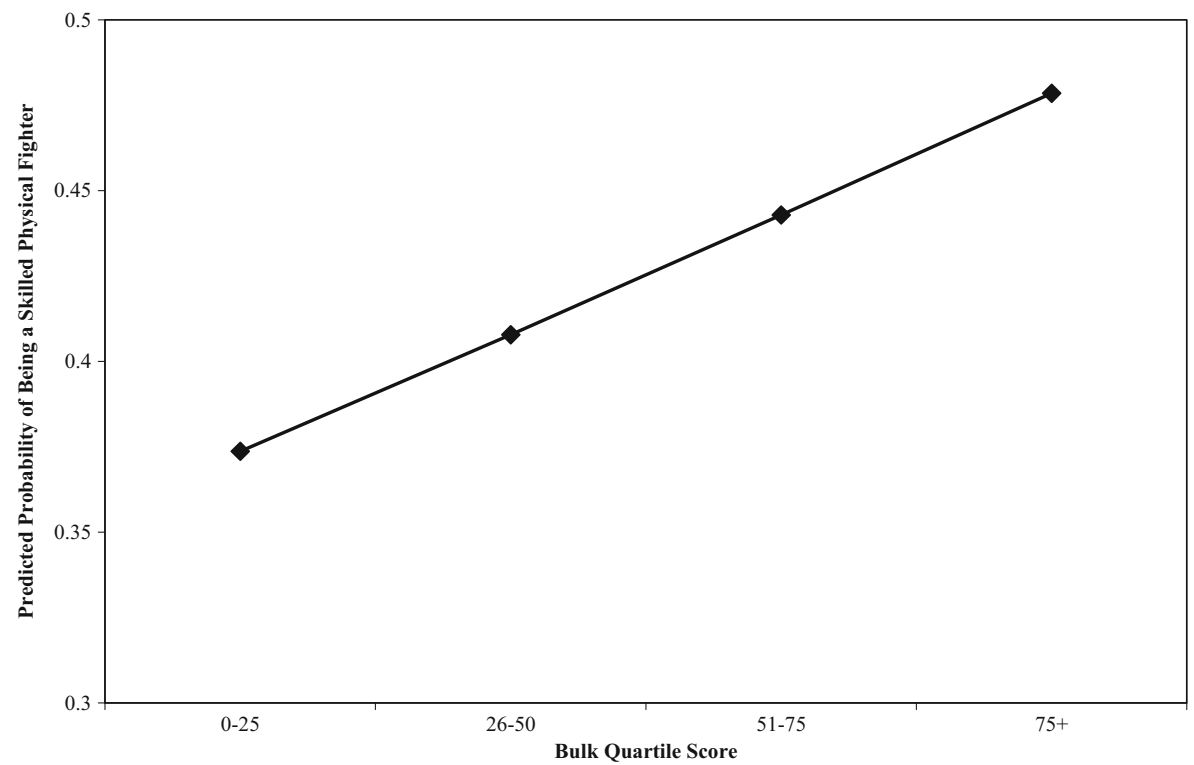

Fig. 2 Predicted probabilities of being a skilled physical fighter across different bulk levels. Note: Predicted probabilities generated with age and race set to their means 
the physical factors that might be involved in why some adolescents are more skilled at fighting than others. The current study was designed to address this gap in the literature by examining the potential association between height and physical fighting and bulk and physical fighting. Analyses of males from the Add Health data revealed that taller males and bulkier males were significantly more likely to be skilled physical fighters in comparison with their shorter and less bulky counterparts. To put this finding into perspective, the tallest male in the study was more than $111 \%$ more likely to be a skilled physical fighter when compared to the shortest male in the study. Similarly, males scoring in the highest quartile of bulk were nearly $30 \%$ more likely than males scoring in the lowest quartile of bulk to be classified as a skilled physical fighter. These findings provide strong evidence indicating that physical stature - as measured by height and bulk - is a significant predictor of physical fighting fitness among adolescent males.

While the analysis was able to establish a significant association between height and bulk and physical fighting ability, the precise mechanisms that link physical stature to successful fighting remain undetermined. While admittedly speculative, it is quite possible that height and bulk are visible indicators of physical development, such as the onset of puberty and the degree of progression through it. As males enter into puberty, their bodies are transformed in a number of significant ways that prime them for excelling in physical confrontations. Their skeletal structure, for example, becomes more durable and thus they are more likely to absorb powerful blows without nearly as much damage [12]. At the same time, their upper bodies are becoming stronger, with muscle tissue growth increasing at a significant rate, and they have quicker reaction times and are more accurate at tasks that demand hand-eye coordination [12]. The end result is that height and bulk might be related to successful fighting ability largely because both measures are proxy indicators of strength and power that accompany the onset of puberty. This finding would fall in line with emerging research showing that other characteristics, such as voice and facial features, are used to assess the strength and fighting abilities of others [33]. Height and bulk therefore might be added to the list of visible manifestations that can be used to determine fighting abilities in adolescent males.

Some critics may argue that too much attention is being paid to the biological underpinnings of height and bulk without much homage being paid to the sociological factors that might also explain this association. According to this logic, it might be the case that taller and bulkier males are primed to be more aggressive, violent, and antisocial $[20,31]$. Throughout their lives, these taller and bulkier males may simply perceive that they are better fighters and are more likely to use violence as one of their first lines of defense when encountering a problem or dispute. Over time, their experience in physical fighting has made them more skilled fighters, but as can be seen, these skills have nothing to do with biological endowment, but rather with learning how to be an effective fighter. Keep in mind that we were able to partially address this possibility in the analysis by examining whether height and bulk were predictive of being a physical fighter (i.e., being in a fight without any measurement of the outcome of the fight). The results of these analyses revealed that there was no link between height and bulk and the probability of being in a fight. This finding is somewhat at odds with some of the existing literature showing that measures of physical stature are linked to aggression, violence, and fighting (e.g., [31]). Why the 
findings in this study are different from those reported in previous research is not entirely clear. It is possible that since our analyses were based on a nationally representative sample of adolescent males, the pathways to aggression or fighting are different from those that are based on convenience samples or clinical-based samples. Future research would benefit by examining the link between physical stature and the probability of simply engaging in a physical fight. Whatever the reason for the differences in findings, the evidence points to the very real possibility that height and bulk are indicators of being a skilled physical fighter because of the biological advantages that are associated with these physical attributes and others that may covary with them.

In a similar vein, existing research showing that taller and bulkier males are more violent could provide an alternative interpretation of the findings. In this case, these more violent males - who are taller and bulkier - might be more prone to use weapons, such as knives and guns, in a fight and thus are more likely to emerge from the fight a victor with their adversary being seriously injured. We performed a series of supplemental analyses to examine this possibility, and our results revealed that the effect of height and bulk on being a skilled physical fighter remained significant even after controlling for the effects of weapon use in fights. Indeed, the analyses also revealed a non-significant trend toward shorter and less bulky men being more likely to use weapons in a fight. Perhaps males who are lacking in physical size are more likely to use weapons as a way to minimize the differences in physical power between them and taller, bulkier men [25].

Whatever the mechanisms are that link height and bulk to being a successful physical fighter, our results add to an emerging body of literature showing that there are physical attributes that act as visible signs of being a skilled physical fighter in males [12]. Even so, our findings should be viewed with caution due to a number of limitations that need to be addressed in future research. First, the Add Health data did not include any information about who the physical fight was against. Ideally, it would have been beneficial to know the height and bulk of the adversaries that were fought by the male subjects. That way, we would have been able to predict the outcome of the physical encounter based on the height and bulk of both individuals in the fight. Second, due to data constraints, we were forced to rely only on the measures of height and bulk to assess physical stature as proxies for fighting skills. While this measurement strategy may be an advantage over previously used measures of fighting ability, such as hand grip strength [34], a more comprehensive measure would have been more ideal. Follow-up research should build upon these findings to determine the extent to which other skills, such as hand-eye coordination and objective measures of muscle strength, are able to predict being a skilled physical fighter among adolescent males. Third, we relied on self-reports of physical fighting and the types of injuries that occurred during the fight. One of the questions asked directly about whether the respondent's adversary was hurt badly enough to need medical care. While selfreports of antisocial behavior have been widely used and been found to be reliable and valid [35], it is quite possible that the subjects were unable to accurately appraise the extent of injuries they had inflicted on their adversary.

Fighting abilities had profound implications in the evolutionary past and, in some geographical areas, continue to have significant ramifications in contemporary societies. Physical attributes advertising differences in fitness for fighting likely deter 
potential victimizers from attacking some individuals and, at the same time, likely attract potential victimizers to prey on others. Height and bulk are two physical characteristics that are easily observable and are easily appraised without any type of scientific instrumentation. As a result, it is not surprising that height and bulk are likely two of the many biologically influenced traits that can be used to provide a relatively crude, albeit somewhat accurate, appraisal of fighting ability among adolescent males.

\section{Compliance with ethical standards}

Conflict of interest The authors declare that they have no conflict of interest.

\section{References}

1. Farrington, D. P. (1986). Age and crime. Crime and Justice, 7, 189-250.

2. Moffitt, T. E. (1993). Adolescence-limited and life-course persistent antisocial behavior: a developmental taxonomy. Psychological Review, 100, 674-701.

3. Nagin, D. S., Farrington, D. P., \& Moffitt, T. E. (1995). Life-course trajectories of different types of offenders. Criminology, 33, 111-139.

4. Pickett, W., Molcho, M., Elgar, F. J., Brooks, F., De Looze, M., Rathmann, K., et al. (2013). Trends and socioeconomic correlates of adolescent physical fighting in 30 countries. Pediatrics, 131, e18-e26.

5. Schwartz, J. A., \& Beaver, K. M. (2013). Serious fighting-related injuries produce a significant reduction in intelligence. Journal of Adolescent Health. Forthcoming.

6. Kodjo, C. M., Auinger, P., \& Ryan, S. A. (2004). Prevalence of, and factors associated with, adolescent physical fighting while under the influence of alcohol or drugs. Journal of Adolescent Health, 35, 346e11.

7. Rudatsikira, E., Muula, A. S., \& Siziya, S. (2008). Variables associated with physical fighting among US high-school students. Clinical Practice and Epidemiology in Mental Health, 4, 16.

8. Swahn, M. H., \& Donovan, J. E. (2006). Alcohol and violence: comparison of the psychosocial correlates of adolescent involvement in alcohol-related physical fighting versus other physical fighting. Addictive Behaviors, 31, 2014-2029.

9. Espelage, D. L., Holt, M. K., \& Henkel, R. R. (2003). Examination of peer-group contextual effects on aggression during early adolescence. Child Development, 74, 205-220.

10. Colder, C. R., Mott, J., Levy, S., \& Flay, B. (2000). The relation of perceived neighborhood danger to childhood aggression: a test of mediating mechanisms. American Journal of Community Psychology, 28, 83-103.

11. Wright, D. R., \& Fitzpatrick, K. M. (2006). Social capital and adolescent violent behavior: correlates of fighting and weapon use among secondary school students. Social Forces, 84, 1435-1453.

12. Sell, A., Hone, L. S. E., \& Pound, N. (2012). The importance of physical strength to human males. Human Nature, 23, 30-44.

13. Stirrat, M., Stulp, G., \& Pollet, T. V. (2012). Male facial width is associated with death by contact violence: narrow-faced males are more likely to die from contact violence. Evolution and Human Behavior, 33, 551-556.

14. Třebický, V., Havlíček, J., Roberts, S. C., Little, A. C., \& Klasel, K. (2013). Perceived aggressiveness predicts fighting performance in mixed-martial-arts fighters. Psychological Science, 24, 1664-1672.

15. Zilioli, S., Sell, A. N., Stirrat, M., Jagore, J., Vickermna, W., \& Watson, N. V. (2015). Face of a fighter: bizygomatic width as a cue of formadibility. Aggressive Behavior, 41, 322-330.

16. Scholte, R. H., Engels, R. C., Overbeek, G., deKemp, R. A., \& Haselager, G. J. (2007). Stability in bullying and victimization and its association with social adjustment in childhood and adolescence. Journal of Abnormal Child Psychology, 35, 217-228.

17. Arseneault, L., Bowes, L., \& Shakoor, S. (2010). Bullying victimization in youths and mental health problems: 'much ado about nothing'. Psychological Medicine, 40, 717-729. 
18. Biebl, S. J., DiLalla, L. F., Davis, E. K., Lynch, K. A., \& Shinn, S. O. (2011). Longitudinal associations among peer victimization and physical and mental health problems. Journal of Pediatric Psychiatry, 36, 868-877.

19. Turner, H. A., Finkelhor, D., \& Ormrod, R. (2006). The effect of lifetime victimization on the mental health of children and adolescents. Social Science Medicine, 62, 13-27.

20. Ishikawa, S. S., Raine, A., Lencz, T., Bihrle, S., \& LaCassee, L. (2001). Increased height and bulk in antisocial personality disorder and its subtypes. Psychiatry Research, 105, 211-219.

21. Archer, J., \& Thanzami, V. (2007). The relation between physical aggression, size, and strength, among a sample of young Indian men. Personality and Individual Differences, 43, 627-633.

22. Tremblay, R. E., Schaal, B., Boulerice, B., Arseneault, L., Soussignan, R. G., Paquette, D., \& Laurent, D. (1998). Testosterone, physical aggression, dominance, and physical development in early adolescence. International Journal of Behavioral Development, 22, 753-777.

23. Pellegrini, A. D. (2008). The roles of aggressive and affiliative behaviors in resource control: a behavioral ecological perspective. Developmental Review, 28, 461-487.

24. Sell, A., Tooby, J., \& Cosmides, L. (2009). Formidability and the logic of human anger. Proceedings of the National Academy of Sciences, 106, 15073-15078.

25. Felson, R. B. (1996). Big people hit little people: sex differences in physical power and interpersonal violence. Criminology, 34, 433-452.

26. Udry, J. R. (2003). The National Longitudinal Study of Adolescent Health (Add Health), Wave III, 20012002.

27. Harris, K. M., Florey, F., Tabor, J., Bearman, P. S., Jones, J., \& Udry, R. J. (2003). The National Longitudinal Study of Adolescent Health: Research Design [www document]. URL: http://www.cpc. unc.edu/projects/addhealth/design.

28. Harris, K. M., Halpern, C. T., Smolen, A., \& Haberstick, B. C. (2006). The National Longitudinal Study of Adolescent Health (Add Health) Twin Data. Twin Research and Human Genetics, 9, 988-997.

29. Resnick, M. D., Bearman, P. S., Blum, R. W., Bauman, K. E., Harris, K. M., Jones, J., et al. (1997). Protecting adolescents from harm: findings from the National Longitudinal Study of Adolescent Health. Journal of the American Medical Association, 278, 823-832.

30. DiLalla, L. F., \& Gottesman, I. I. (1989). Heterogeneity of causes for delinquency and criminality: lifespan perspectives. Development and Psychopathology, 1, 339-349.

31. Raine, A., Reynolds, C., Venables, P. H., Mednick, S. A., \& Farrington, D. P. (1998). Fearlessness, stimulation-seeking, and large body size at age 3 years as early predispositions to childhood aggression at age 11 years. Archives of General Psychiatry, 55, 745-751.

32. Fessler, D. M., Holbrook, C., \& Snyder, J. K. (2012). Weapons make the man (larger): formidability is represented as size and strength in humans. PLOS ONE, 7, e32751. doi:10.1371/journal.pone.0032751.

33. Sell, A., Bryant, G. A., Cosmides, L., Tooby, J., Sznycer, D., Von Rueden, C., et al. (2010). Adaptations in humans for assessing physical strength from the voice. Proceedings of the Royal Society B: Biological Sciences, 277, 3509-3518.

34. Muñoz-Reyes, J. A., Gil-Burmann, C., Fink, B., \& Turiegano, E. (2012). Physical strength, fighting ability, and aggressiveness in adolescents. American Journal of Human Biology, 24, 611-617.

35. Thornberry, T. P., \& Krohn, M. D. (2000). The self-report method for measuring delinquency and crime. Criminal Justice, 4, 33-83. 